Journal homepage:

http://www.bsu.edu.eg/bsujournals/JVMR.aspx

Online ISSN: 2357-0520

Print ISSN: 2357-0512

Original Research Article

\title{
Nosocomial Antiseptics And Disinfectants Resistant Bacteria: microbiological and histopathological studies
}

Maged S. Ahmad ${ }^{(1)}:$ Medhat Abdel Fatath $^{(2)} \quad:$ Khalid A. El-Nesr $^{(3)}$ and Mohamed Ramadan ${ }^{(4)}$

1, 2,4 Department of Botany, faculty of Sciences, Beni-Suef University , 3 Department of Pathology, Faculty of Veterinary Medicine, Beni-Suef University, BeniSuef.

\begin{abstract}
This study contains evidence-based recommendations for the prevention of hospital acquired infections. Hospital acquired infections are a major cause of mortality and morbidity and provide challenge to clinicians. Measures of infection control included identifying patients at risk of nosocomial infections. Antiseptics and disinfectants are used extensively in hospitals and other health care settings for a variety of topical and hard-surface applications. In particular, they are an essential part of infection control practices and aid in the prevention of nosocomial infection. This study investigated the nosocomial infection via isolation and identification of bacterial pathogens, the effect of detergents against isolated bacteria, and describes the histopathological tissue changes induced by the isolated bacteria in vivo study. Some bacteria resistant to disinfectants were prevalent and these bacteria had different effects on the human, Different pathological changes were seen experimentally by inoculation of these bacteria in mice.
\end{abstract}

\footnotetext{
*Corresponding author. Department of Pathology, Faculty of Veterinary Medicine, Beni-Suef University, BeniSuef.
}

ARTICLE INFO

Article history:

Received

$11 / 2018$

Accepted 12/2018

Online 12/2018

\section{Keywords:}

Nosocomial,

Antiseptics,

Resistant Bacteria 


\section{Introduction}

Nosocomial infection (hospital acquired infection (HAI)) is an infection that is acquired in hospital or other health care facility. Sometimes, it's called a health careassociated infection (HCAl). The centers of disease control and prevention, in the United States, estimated roughly 107 million hospital-associated infections, from all types of microorganism, including bacteria and fungi combined that cause or contribute to 55000 deaths each year. But in Europe, the category of gram-negative has been incriminated to account for two-third of the 25000 deaths each year. Nosocomial infection can cause severe pulmonary and urinary tract infection (Wilks, et al., 2005) (HAls) is a major safety concern for both health care providers and the patients. Considering morbidity, mortality, increased length of stay and the cost, efforts should be made to make the hospitals as safe as possible by preventing such infections. These study have been developed for health care personnel involved in patient care in wards and critical care areas and for persons responsible for surveillance and control of infections in hospital (Kjellerup, 2015).
Mounting concerns over the potential for microbial contamination and infection risks in the food and general consumer markets have also led to increased use of antiseptics and disinfectants by the general public. A wide variety of active chemical agents (or "biocides") are found in these products, many of which have been used for hundreds of years for antisepsis, disinfection, and preservation .Despite this, less is known about the mode of action of these active agents than about antibiotics. In general, biocides have a broader spectrum of activity than antibiotics, and, while antibiotics tend to have specific intracellular targets, biocides may have multiple targets. The widespread use of antiseptic and disinfectant products has prompted some speculation on the development of microbial resistance, in particular cross-resistance to antibiotics. This review considers what is known about the mode of action of, and mechanisms of microbial resistance to, antiseptics and disinfectants and attempts, wherever possible, to relate current knowledge to the clinical environment (Larson, 1996).

This study was carried out to investigate the nosocomial infection via isolation and identification of bacterial isolates, the effect 
of detergents against isolated bacteria, and investigate the tissue changes induced by the isolated bacteria in vivo study

\section{Materials and methods}

\section{(1) collecting sample:}

All samples are collected from some Beni Suef hospitals(governmental hospitals, private hospitals eg Alzahraa hispital ) from Icu, operating rooms, patient rooms, during the period from March 2012 to April 2015. The study included 300 samples. Which collected from different places that included many of fungi and different types of bacteria.

\section{Inoculation of samples:}

Preparation of isolates and inoculate under a septic condition on blood agar, maconkey agar, nutrient broth agar, in the EINahda University Faculty of pharmacy microbiological labs., (Pannutti, and, Grinbaum, 1995).

identification of bacteria:

Isolates were identified by microbiological techniques; Gram staining and biochemical tests. (Gram, 1884)

(2) Culture media for isolation and identification of bacteria:

Nutrient broth (NB) medium (Lapage et al., 1970):
Macconkey agar (MackConkey, 1905):

Blood agar medium (Hoppe and

Schlagenhauf, 1989):

(3) Staining reagents:

- Gram stain (Gram, 1884).

\section{(4) Detergents:}

- Cidex: is a common designation for a variety of solutions uses for aminierobial or disinfection purposes.

- Cidex op A, atrase name for a solution with phthaldehyde as active ingredient

- Nu-Cidex, with peracetic acid.

- Cidex plus, with 91 wateraldehyde

\section{Glutaraldehyde}

Glutaraldehyde, sold under the brandname Glutaral among others, is a disinfectant and medication. As a disinfectant it is used to sterilize surgical instruments and other areas. As a medication it is used to treat warts on the bottom of the feet. It is applied as a liquid.

Side effects include skin irritation. If exposed to large amounts nausea, headache, and shortness of breath may occur. Protective equipment is recommended when used. Glutaraldehyde is effective against a range of microorganisms including spores. It works by a number of mechanisms. Glutaraldehyde came into medical use in the 1960s. it is on the World Health 
organization's List of Essential Medicines, the most effective and safe medicines needed in a health system. The wholesale cost in the developing world is about 1.50 to 7.40 USD per liter of $2 \%$ solution. It is sold under a number of brand names including Cidex. There are a number of other commercial uses such as leather tanning.

\section{Povidone-iodine (Betadine)}

- Povidone-iodine (pvp-1), also Known as iodopovidne, is an antiseptic for skin disinfection before and after surgery. It may be used as both for disinfection the skin of the patient and the hands of the healthcare providers. It may also be used for minor wounds. It may be applied to the skin as a liquid or a powder.

- Povidone-iodine is a chemical complex of povidone and the elemetn iodine. It contains from $9 \%$ to $12 \%$ available iodine. It works by releasing iodine which results in the death of range of microorganisms.

- Povidone-iodine came into commercial use in 1955. It is on the world Health organization's list of essential Medicine. The most effective and safe medicines needed in aheath system.

It is sold under a number of brand names including Betadine

Study the effect of detergents on isolated bacteria
Cidex 4\%: Mix Cidex with Media which inoculated by bacteria that discovered,

Take some of CIDEX after 16 days from mixing and inoculate some of bacterial isolates to determined which microorganism resistant to it Use CIDEX with different concentration $2 \%, 3 \%, 4 \%$ and inoculate some of bacterial isolates to determined which microorganism resistant to CIDEX.

\section{Betadin 10\% :-}

- In our study we began to use Bettadine by concentration $10 \%$ (this concentration used in all private and general hospital disinfectant)

a- Mixing with different types of media and inoculate some of bacterial isolates to determined which microorganism resistance to Bettadine.

b- Repeat the past method but increasing the concentration of Bettadine to $20 \%$.

C- Repeat the past method but increasing the concentration of Bettadine to $30 \%$ to determine the lethal doses of Bettadine.

\section{Dettol 10\% :-}

a- Used Dettol by concentration 10\% (this concentration used generally in all types of hospitals), mix Dettol with different type of media and inoculate some of bacterial cell to determined which microorganism resist of Dettol 
b- Repeat the past method but increasing the concentration of Dettol to $15 \%$ and determined which microorganism resistance to this concentration .

c- Repeat the past method and increase the concentration of Dettol $20 \%$ and determined which microorganism resistance to this concentration

\section{Experimental study.}

\section{Mice.}

Thirty six albino mice, aged 6-8 obtained from national cancer institute, Cairo, Egypt. Mice were bred in the animal house, faculty of veterinary, Beni-Suef University. They were maintained under 12 hour light dark cycle at temperature of $22+2 \& \mathrm{C}$ and fed with standard diet and water adlibitum. The study was conducted according to the ethical forms approved by the animal ethics committee guide lines of Beni Suef University.

\section{Mouse lethality studies:}

Mice were sensitized to the effects of Gram negative bacteria ( $K$. peneumnia) and Gram positive bacteria (St. aureus) by the intraperiatoneal injection of different bacterial concentrations varying from $10^{6} \mathrm{CFU} / \mathrm{m} / \mathrm{ml}$ to $10^{10} \mathrm{CFU} / \mathrm{ml}$.

Mortality and morbidity was recorded after 1 week. From injection. The 50\% lethal dose
(LD 50) was determined by the method of (Read and Muench, 1938).

\section{Samples collections:}

- The scarified animals were dissected under aseptic condition. Spleen, liver, lung and kidney were collected at sterilized falcons tubes contain $3 \mathrm{ml}$ salin for each organ to measure bacterial load, and other organs collected in sterlized cups containing formaline $10 \%$ for histobathlogical studies.

- Determination of bacterial load in mice organs.

- Each organ was homogenized in a tissue grinder or homegenzer with $3 \mathrm{ml}$ sterilized saline solution the homogenate was serially diluted and $0.1 \mathrm{ml}$ was plated on Macconke,s agar plates.

- Some parts of organs are collected at sterilized falcons tubes containing $3 \mathrm{ml}$ sterilized slaine for measuring bacterial load.

\section{Histopathological examination:}

Tissue samples were collected from lung, kidney and liver of all animals. These specimens were fixed in neutral formalin $10 \%$ for $48 \mathrm{hs}$. After fixation, the sample underwent washing, dehydration in graduated ethyl alcohol, cleaned in xylene, and embedded in paraffin wax. After blocking, 5 microns tissue section were 
mounted on clean glass slides and stained with Hematoxyline and eosin according to Bancroft and Gamble (2008).

\section{Results}

Infection rate was variable among patient room, operation room, operation tool and ICU between general \& private hospital (fig. 1\&2)

Identify microorganism causing nosocomial infection in collected isolates
From our study, there was a wide variation in the rates and types of microorganism that causing nosocomial infection, gram (+ve) bacteria are the most common cause of nosocomial infection with Staphylococcus aureus that reported rate about $50 \%$ with the pathogens causing infection, while gram (-ve) bacteria especially klebsiella pneumonia reported about 35\% fungal infection reported about $10 \%$, finally yeast infection reported about 5\%. ( Fig. 3 ) 
Table (1) effect of detergents on resistance strains of gram ( $+v)$ bacteria(staph aureus) and gram (-v) bacteria (k.pneumonia)

\begin{tabular}{|c|c|c|}
\hline Detergents & Gram-ve & gram+ve \\
\hline cidex $4 \%$ after preparing & no growth $0 \%$ & no growth $0 \%$ \\
\hline cidex $3 \%$ after preparing & no growth $0 \%$ & no growth $0 \%$ \\
\hline cidex $2 \%$ after preparing & no growth $0 \%$ & no growth $0 \%$ \\
\hline cidex $4 \%$ after 16 from preparing & no growth $0 \%$ & no growth $0 \%$ \\
\hline betadine $10 \%$ & Positive $40 \%$ & Positive $60 \%$ \\
\hline betadine20\% & weak positive $10 \%$ & Positive $45 \%$ \\
\hline betadine $30 \%$ & no growth $0 \%$ & weak growth \\
\hline detol $10 \%$ & Positive $50 \%$ & Positive $50 \%$ \\
\hline detol $15 \%$ & weak positive $20 \%$ & Positive $60 \%$ \\
\hline detol $20 \%$ & no growth $0 \%$ & no growth $0 \%$ \\
\hline
\end{tabular}

\section{Effect of resistance strains of Gram (+v) bacteria(S. aureus) and Gram (-ve) bacteria (K.pneumonia) on lab animals. ( fig 5)}

\section{Histopathological examination:}

\section{Control animals:}

The lung of control animals appeared more or less normal (fig.6). The bronchi and bronchioles were lined by columnar epithelium. Alveiolei had normal alveolar cells. The liver showed normal histological structures (fig.7). The hepatic lobules had normal central vein and sinusoids. The hepatocytes appeared polyhedral and arranged in column. The kidneys had normal nephrons and collecting tubules (fig.8). The lining epithelium appeared more or less normal. The interstitial areas showed normal histologic structures.
Klebsilla. - infected mice:

\section{Lungs:}

Histopathology of mouse lung experimentally infected with klebsiella showed mild to moderate inflammatory reactions (fig9). Focal interstitial infiltrations with neutrophils and macrophages at one week after infection were predominating. Additional, predominantly, perivascular lymphocytic infiltrations were seen around small and medium-sized blood vessels (fig.10). The blood vessels were dilated and congested (fig. 11). In some areas, the interalveolar septa were thickened on expense of the 
alveolar lumen. Oedamtous changes were also seen in some areas. The bronchioles and bronchi in the affected areas or in the vicinity to the areas of inflammation had mild to moderate degeneration of the lining epithelium with perbronchial lecuocytic infiltrations (fig.12\&13) and accumulation of inflammatory exudates within their lumen. Later on, these changes were still prominent at 15 days but were more severe (fig.14).

\section{Liver:}

After the first week of infection, the hepatic parenchyma showed variable degrees of degenerative changes especially vacuolar degeneration (hydropic degeneration) at the periphery of the hepatic lobules (fig.15). Mild congestion was seen in the blood vessels and hepatic sinusoids. No lecuocytic infiltrations were found. After 2 weeks, congruent changes were found (fig, 16).

\section{Kidney:}

After one week, The renal tubules had mild degree of degenerations especially the proximal convoluted tubules. The blood vessels were mildly dilated and congested (fig.17). In a few cases, focal interstitial nephritis was seen (fig. 18). Later, after 2 weeks, severe congestion with marked dilatation of blood vessels with early necrobiotic changes could be seen (fig. 19).

\section{Staph.-infected mice:}

\section{Lung:}

After seven days of inoculation, aggregates of neutrophils were found in the interstitial septa especially in the areas neighboring to the bronchi and bronchiols (fig.20). The blood vessels were dilated and congested (fig. 21) with a accumulation of lecucocytes around them. Two weeks days after inoculation, less advanced signs of pneumonia and bronchitis were found (fig. 22). The bronchial lumens were partially or totally occluded with tissue debris and inflammatory exudates. Peribronchial infiltrates were also seen

\section{Liver:}

In the early days of the experiment (seven days), very mild degenerative changes could be demonstrated (hydropic degeneration with mild dilatation of hepatic sinusoids (fig.23). After 15 days, the hepatic parenchyma appeared more or less normal with minimal pathological alterations (fig. 24).

\section{Kidney:}

Seven days post infection, the renal tubules has minimal pathological changes in the form of cloudy swelling and hydropic degeneration with mild congestion of blood vessels (fig. 25). Later on (after 15 days) these lesions become more pronounced especially the congested blood vessels (fig. 26). 


\section{Klebsilla\&Staph}

\section{Lung:}

In comparison to $\mathrm{K}$ or $\mathrm{S}$ infected groups, the lung of this group after one week showed more advanced pathological alterations. Marked focal interstitial leucocytic infiltrations were prevalent allover the lung tissue (fig. 27). The blood vessels were dilated congested (fig. 28). After 15 days, the leucocytes infiltrated a wider areas than after one week (fig. 29). Also, prominent perivascular cuffing was found (fig. 30).

\section{Liver:}

After one week, the pathological alterations were slightly more pronounced than the previous groups. Vacuolar degeneration was

\section{$\underline{\text { Discussion }}$}

Health - care associated infection ( HAIS) one of the most common words in the intensive care unit (ICU) where doctors treat serious diseases about 1 in 10 of the people adimitted to hospital will contract a (HAl), they're also associated with significant morbidity, mortality, and hospital costs .

(Wilks et al., 2005). investigated that in the united states, the centers of Disease control and prevention estimated roughly 107 million hospital - associated infection, from all types of microorganism, including bacteria and fungi combined, cause or predominant in the whole parenchyma with marked sinusoidal dilatation and congestion (fig. 31). After 15 days, the lesions were less severe and appeared in the form of mild degenerative changes (fig. 32).

\section{Kidney:}

In the early time, the blood vessels were markedly dilated and congested with variable degrees of glomerulonephrosis and tubulonephrosis. The interstitial blood vessels were moderately congested (fig. 33). Later, the pathological changes were in the form marked congestions of blood vessels (fig.34) and glumerulonephrosis

contribute to 55,000 deaths each year in Europe, where hospital surveys have been conducted, the category of gram-negative have been conducted, the category of gram -negative infection are estimated to account for two - third of the 25000 deaths each year

Nosocomial infection can cause severe pneumonia and infection of the urinary tract, blood stream and other parts of the body (Kjellerup, 2015)

The current study aimed to introduce an effective manner to control nosocomial infection in different places from hospitals. In order to assess this aim the present study built on three consequent ideas ; the 
first one concerned on identify the different types of microorganism causing nosocomial infection. The second idea was a trial to study the effect of detergent on bacteria which present in hospitals and determined the lethal dose and sub lethal dose. Finally, the third part was study the effect of resistance strain of bacteria on lab animals (K.pneumonia and staph aureus, the most frequent pathogen among nosocomial infection).

in the current study samples were collected from patient room, operation room (wall, operation table, floor, tools, ICU by sterilizing swab) and beganing to identify which microorganism that cause nosocomial infection, we found that a wide variation in the rates of types of microorganism that causing nosocomial infection, gram +ve bacteria are the commonset cause of nosocomial infection with staphylococcus aureus that reported rate about $50 \%$ with pathogenes causing nosocomial infection while gram - ve bacteria especially klebsiella pneumonia reported about 35\%, fungeal infection reported about $10 \%$ and finally yeast infection reported about 5\% A antiseptics are biocid or product that destroy or inhibite the growth of microorganism in or on living tissue (as health care personal hand and surgical scrubs) while disinfectant is a chemical agent that are used on in animate objects or surface disinfectants, all this are sporo static not sporcidal) so we will study different type of detergent that have effect on microbial cell espically (Bacteria) and their different concentration which have effect on Bacterial cell and it's rol in controlling nosocomial infection (Larson, (1996).

In our study, detergent play vital role in controlling nosocomial infection as they used by wide rang in cleaning and disinfection of topical hard surface application.

Cidex by concentration $4 \%$, betadin by concentration $10 \%$, Dettol by concentration $10 \%$ began to use to determine the resistance strain that not affected by this concentration and determined the lethal dose of this detergent.

The current study revealed that some of bacterial cell obtained resistance so some detergent as(Dettol and Betadine),which was in agreement with reports from African and Asian countries, in the other site, modification and hence the cellular sensitivity to antiseptics and disinfectant well be altered to gram +ve bacteria,Gram negative bacteria are more resistant to antiseptics and disinfectant than 
nonsporulating, mycobacterial gram -ve bacteria, hydrophobic mutants of gram negative bacteria tend to be hypersensitive to hydrophobic antibiotics and disinfectants Partial resistance of cell membranes to solubilization with mild detergents and the analysis of isolated detergent-resistant membranes (DRMs) have been used operationally to define membrane domains. Given the multitude of detergents used for this purpose, we sought to investigate whether extraction with different detergents might reflect the same underlying principle of domain formation. We therefore compared the protein and lipid content of DRMs prepared with a variety of detergents from two cell lines. We found that the detergents differ considerably in their ability to selectively solubilize membrane proteins and to enrich sphingolipids and cholesterol over glycerophospholipids as well as saturated over unsaturated phosphatidylcholine. In addition, we observed cell type-dependent variations of the molecular characteristics of DRMs and the effectiveness of particular detergents. These results make it unlikely that different detergents reflect the same aspects of membrane organization and underscore both the structural complexity of cell membranes and the need for more sophisticated analytical tools to understand their architecture (McDonnell and Russell,1999).

Finally we found acquired resistance to antiseptics and disinfectants can arise by either mutation or acquisition of genetic material in the form of plasmids or transposons, it's important to note that "resistance " as a term can often be used loosely and in many cases must be interpreted with some prudence, this is particularly true with MIC analysis

From our study, when increasing concentration of detergent to obtain lethal dose found no growth to gram +ve and gram -ve bacteria but toxic for human if using by this concentration to cleaning and disinfect microorganism by it's different concentration but it's very Staphylococcus aureus and Staphylococcus epidermidis are major human pathogens of increasing importance due to the dissemination of antibiotic-resistant strains. Evidence suggests that the ability to form matrixencased biofilms contributes to the pathogenesis of $S$. aureus and $S$. epidermidis (Russell, 1997). In this study, we investigated the functions of two staphylococcal biofilm matrix polymers: poly-N-acetylglucosamine surface polysaccharide (PNAG) and extracellular 
DNA (ecDNA). We measured the ability of a PNAG-degrading enzyme (dispersin B) and DNase I to inhibit biofilm formation, detach preformed biofilms, and sensitize biofilms to killing by the cationic detergent cetylpyridinium chloride (CPC) in a 96-well microtiter plate assay. When added to growth medium, both dispersin B and DNase I inhibited biofilm formation by both $S$. aureus and $S$. epidermidis. Dispersin B detached preformed $S$. epidermidis biofilms but not $S$. aureus biofilms, whereas DNase I detached $S$. aureus biofilms but not $S$. epidermidis biofilms. Similarly, dispersin B sensitized $S$. epidermidis biofilms to CPC killing, whereas DNase I sensitized S. aureus biofilms to CPC killing. We concluded that PNAG and ec DNA play fundamentally different structural roles in $S$. aureus and S. epidermidis biofilms,(Brumfitt et al., 1985.).

Studying the resistance strain of some bacteria that more contribute in nosocomial infection (S.aureus and k.pneumonia) and there pathogenicity were applied to determine if they were more or less virulent. S. aureus and k.pneumonia were inoculated in lab animals to investigate the tissue changes resulted from. These animals showed different pathological changes in different organs. Acute lung injury was obvious in all animals in the form of mild to severe inflammatory reactions with congestion. The liver and the kidneys of animals infected with one or both organisms showed severe degenerative changes with mild inflammatory reactions.

We found that the bacteria which grow on detergent accepted new properties that can lead to morbidity and mortality for human on long term.

From our study,the prevention of nosocomial infection is the responsibility of all individuals and services providing health care.

Every one must work cooperatively to reduce the risk of infection for patient and staff this includes personal providing direct patient care, management, physical plant, provision of materials and products and training of health workers infection control programmers. (Pannutti, et al., 1995)

Any detergent used in cleaning and disinfection microorganism in hospital must be changed frequently. 


\section{Conclusion}

1. From our study, Nosocomial infections can cause severe pneumonia and infections of the urinary tract, bloodstream and other parts of the body. Many types are difficult to treat with antibiotics. In addition, antibiotic resistance can complicate treatment.

2. Cidex, is a powerful detergent, kills all microorganism

\section{List of figures}

Fig. 1: Showing the rate of infection in general hospital

Fig. 2: Showing the rate of infection in private hospital

Fig. 3 Microorganism causing nosocomial infections

Fig. 4 Identify microorganism in collected isolates

Fig. 5 Bacterial percent cause morbidity and mortility

Fig. 6-8: Tissue sections stained with $\mathrm{H} \& \mathrm{E}$ from lung (6), Liver (7) and Kidney(8) showing normal histological structures (X200)

Fig.9: Lung of a mouse infected with $\mathrm{K}$ after one week showing mild leucocytic infiltration (H\&E-X200)

Fig.10:Lung of a mouse infected with $\mathrm{K}$ after one week showing perivascular cuffing (H\&E-X200)
Fig.11:Lung of a mouse infected with $\mathrm{K}$ after one week showing dilated and congested blood vessels (H\&E-X200)

Fig.12\&13:Lung of a mouse infected with $\mathrm{K}$ after one week showing peribronchial leucocytic aggregaton (H\&E-X200)

Fig.14:Lung of a mouse infected with $\mathrm{K}$ after two weeks showing severe interstitial pneumonia (H\&E-X200)

Fig.15: Liver of a mouse infected with $\mathrm{K}$ after one week showing hydropic degeneration (H\&E-X200)

Fig.16: Liver of a mouse infected with $\mathrm{K}$ after two weeks showing hydropic degeneration (H\&E-X200)

Fig.17: Kidney of a mouse infected with $\mathrm{K}$ after one week showing mild congestion (H\&E-X200)

Fig.18: Kidney of a mouse infected with $\mathrm{K}$ after one week showing focal interstitial nephritis (H\&E-X200)

Fig.19: Kidney of a mouse infected with $\mathrm{K}$ after two weeks showing congestion of blood vessels (H\&E-X200)

Fig.20: Lung of a mouse infected with satph. after one week showing aggregates of neutrophils in inter-alveolar septa (H\&E$\mathrm{X} 200)$

Fig.21: Lung of a mouse infected with staph after one week showing congestion of blood vessels (H\&E-X200) 
Fig.22: Lung of a mouse infected with staph. after 2 weeks had marked signs of pneumonia (increased leucocytic infiltration) (H\&E-X200)

Fig.23: Liver of a mouse infected with Staph. after one week had hydropic degeneration with dilatation of sinusoids (H\&E-X200)

Fig.24: Liver of a mouse infected with Staph. after 2 week showing minimal pathological changes (H\&E-X200)

Fig.25: Kidney of a mouse infected with Staph. after one week showing hydropic degeneration with congestion (H\&E-X200)

Fig.26: Kidney of a mouse infected with Staph. after 2 week marked congestion (H\&E-X200) Fig.27: Lung of a mouse infected with K.\& staph. after one week had marked signs of pneumonia (increased leucocytic infiltration)

\section{(H\&E-X200)}

Fig.28: Lung of a mouse infected with K.\& staph. after one week had congestion of blood vessels (H\&E-X200)

Fig.29: Lung of a mouse infected with K.\& staph. after 2 weeks had wider areas pneumonia (increased leucocytic infiltration) (H\&E-X200) Fig.30: Lung of a mouse infected with K.\& staph. after 2 weeks had prominent perivascular cuffing (H\&E-X200)
Fig.31: Liver of a mouse infected with K.\& staph. after one week had vacuolar degeneration with congestion of blood vessels (H\&E-X200) Fig.32: Liver of a mouse infected with K.\& staph. after 2 weeks had mild degenerative changes (H\&E-X200)

Fig.33: Kidney of a mouse infected with K.\& staph. after one week had moderate congestion of blood vessels (H\&E-X200)

Fig.34: Liver of a mouse infected with K.\& staph. after 2 weeks had marked congestion of blood vessels (H\&E-X200) 


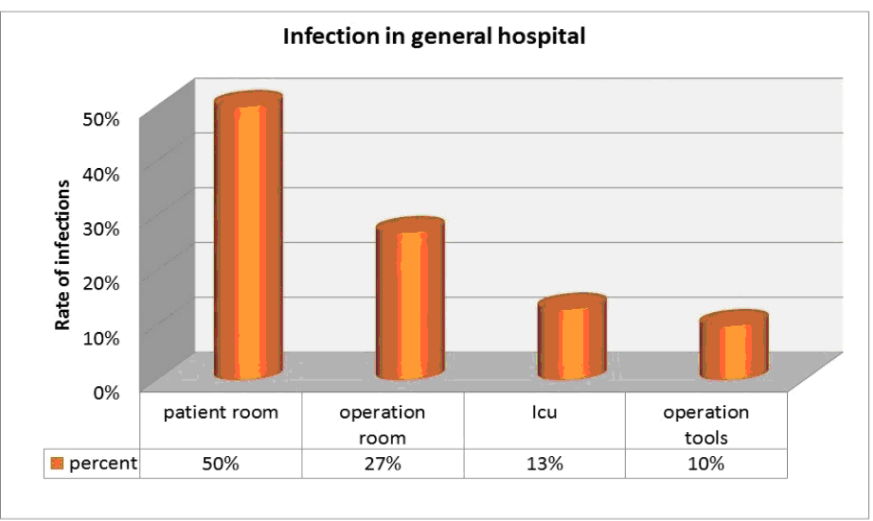

Fig. 1

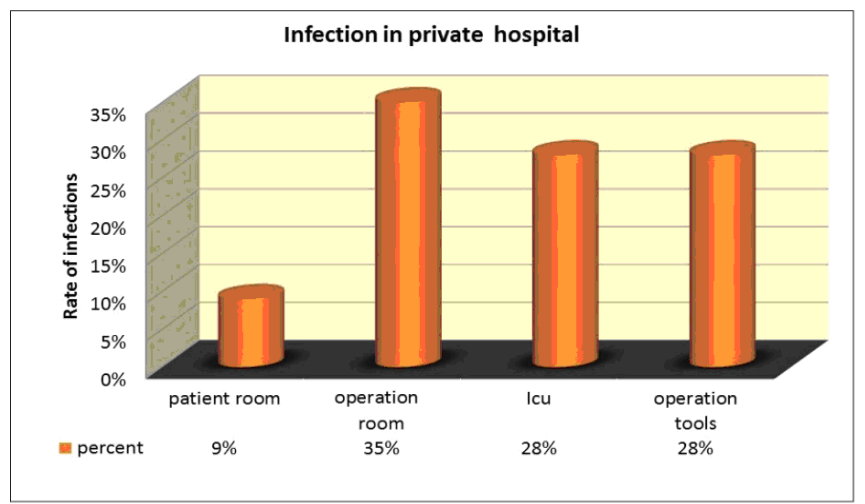

Fig. 2

\section{Identify microorgansm in collected sampel}

Fig. 4

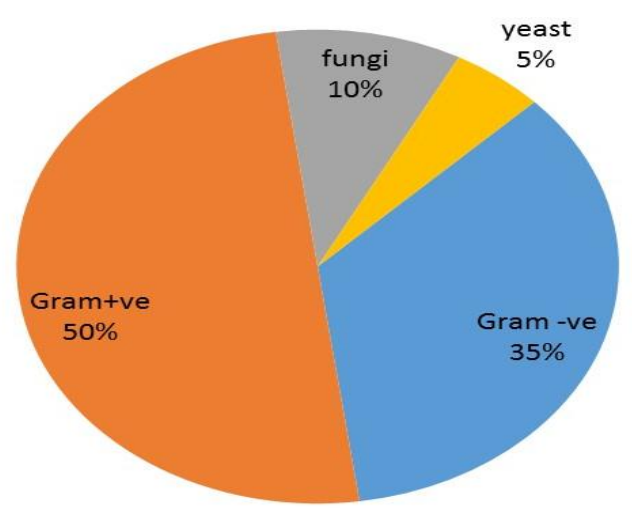

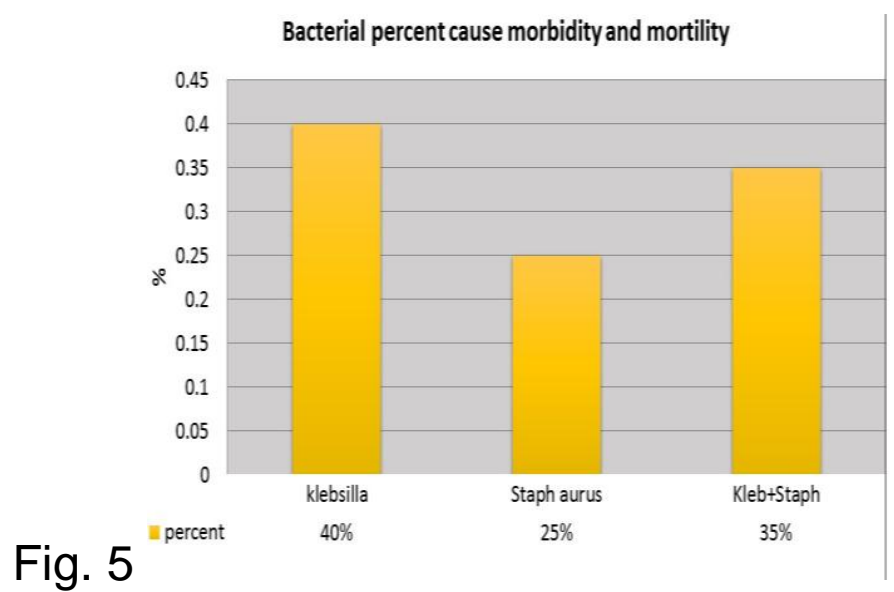

Fig. 3

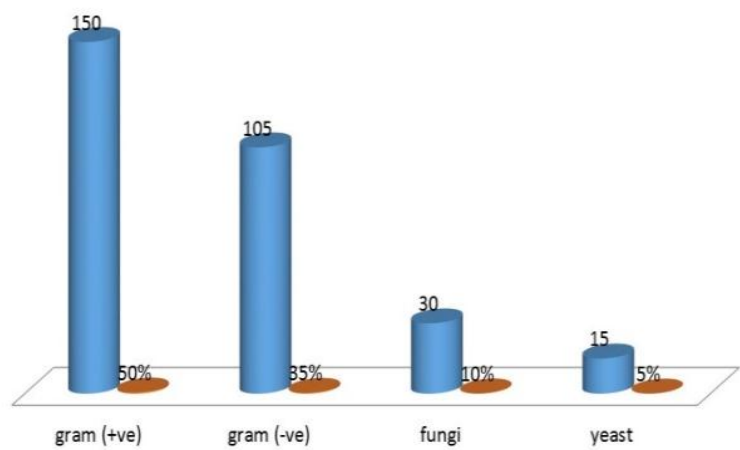




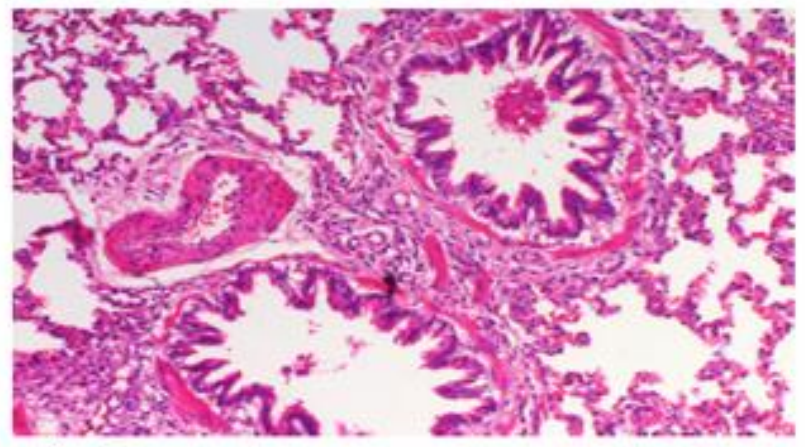

Fig 6

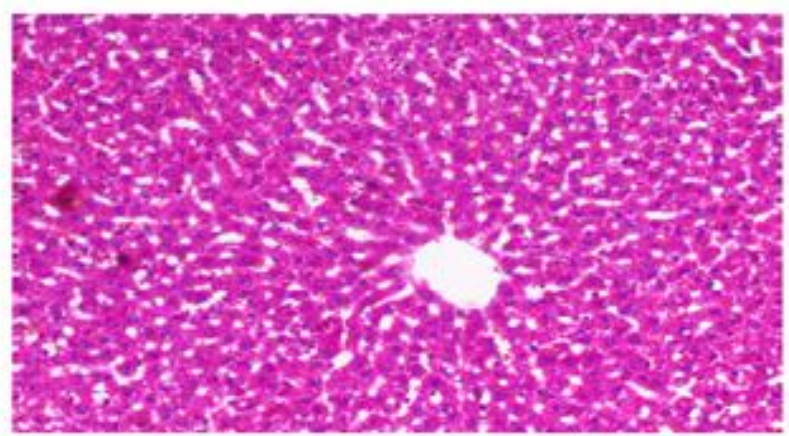

Fig 7

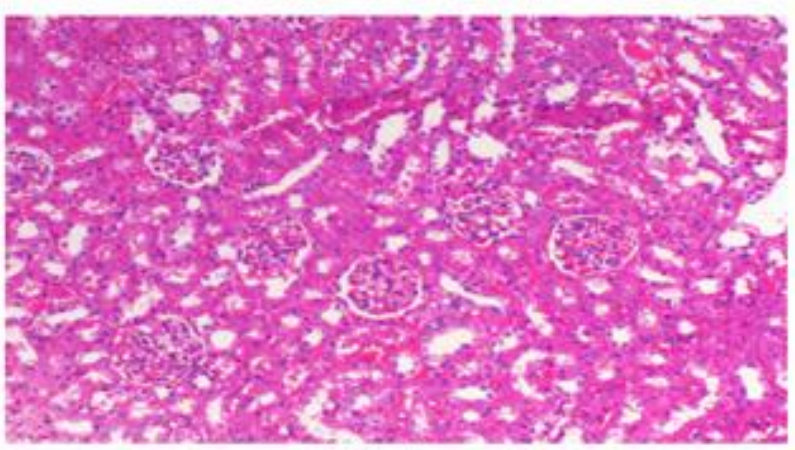

Fig 8

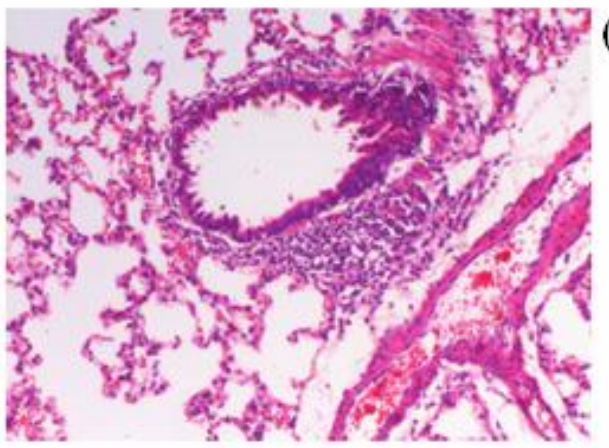

(fig.13)

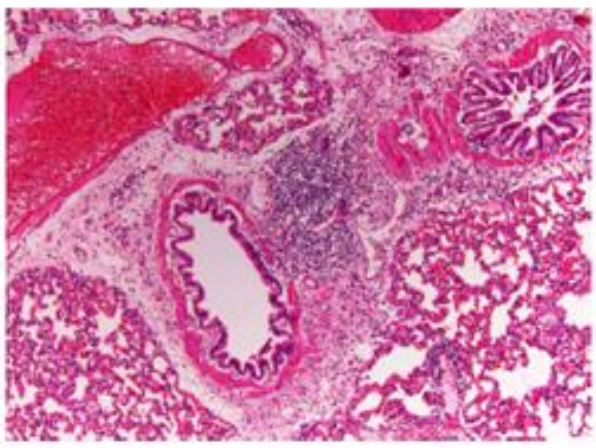

(fig.14)

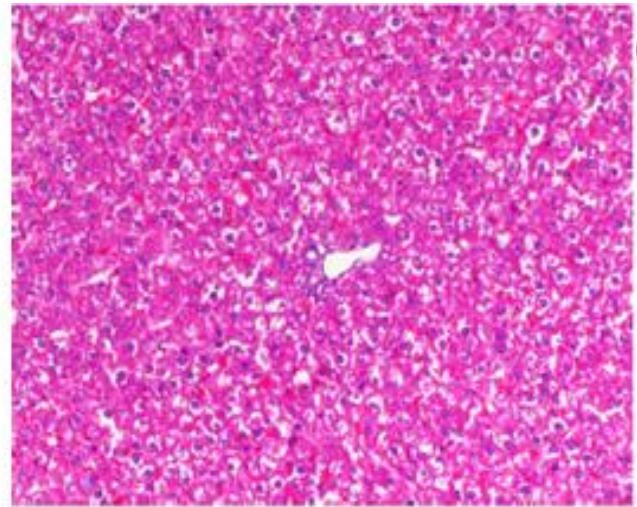

(fig. 15)

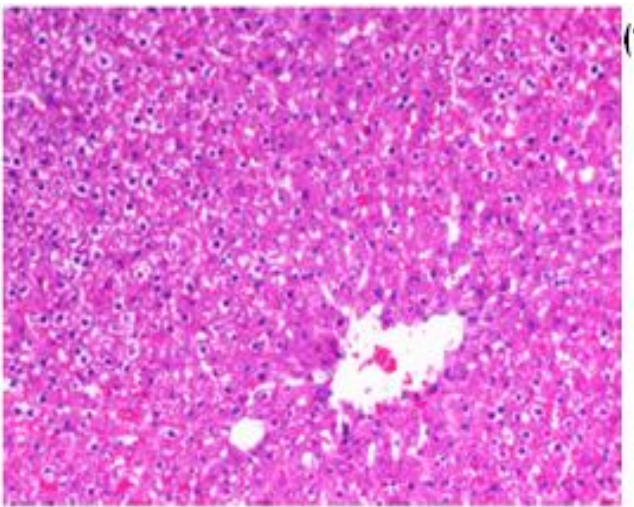

(fig.16) 

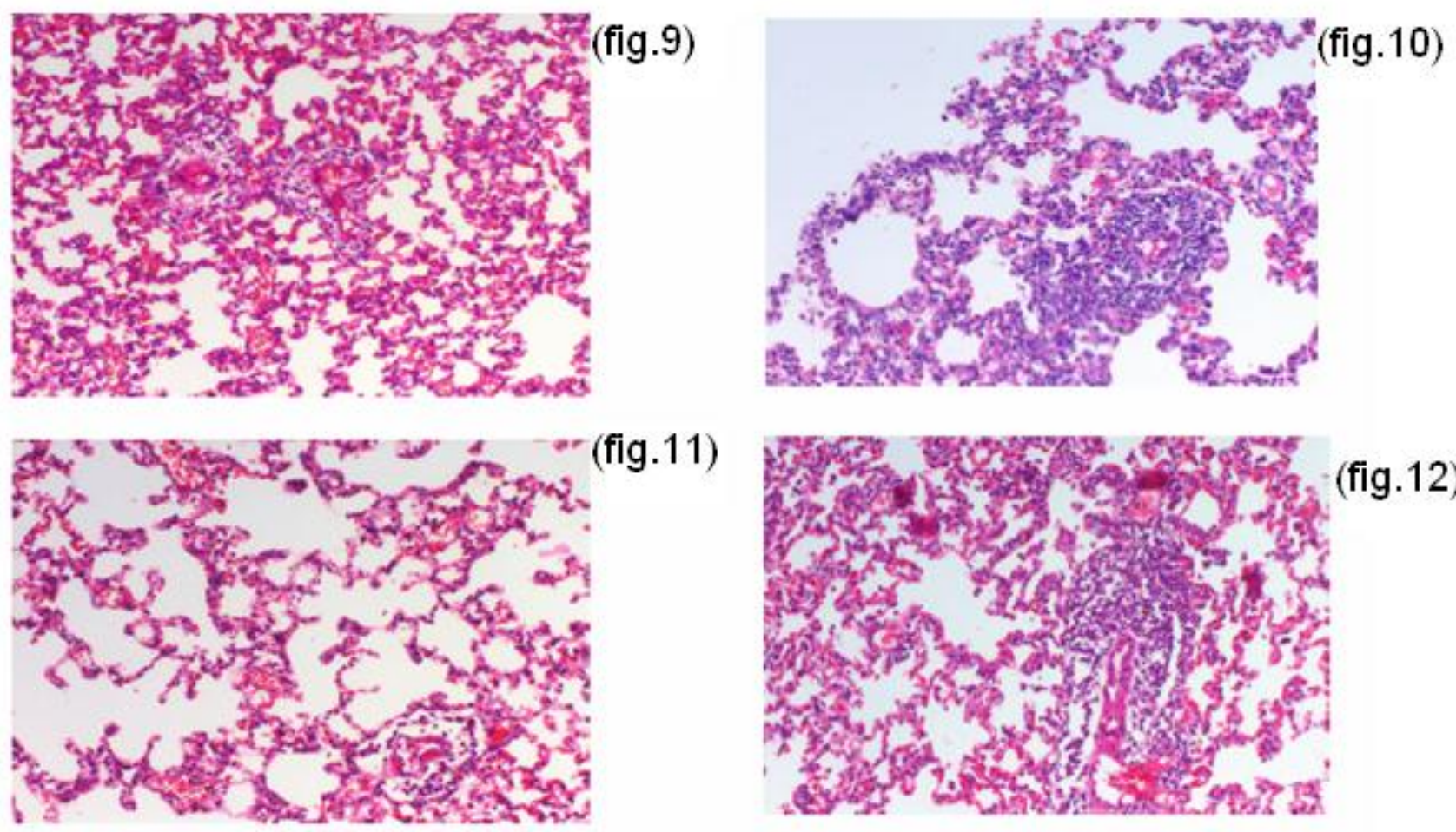

(fig.11)
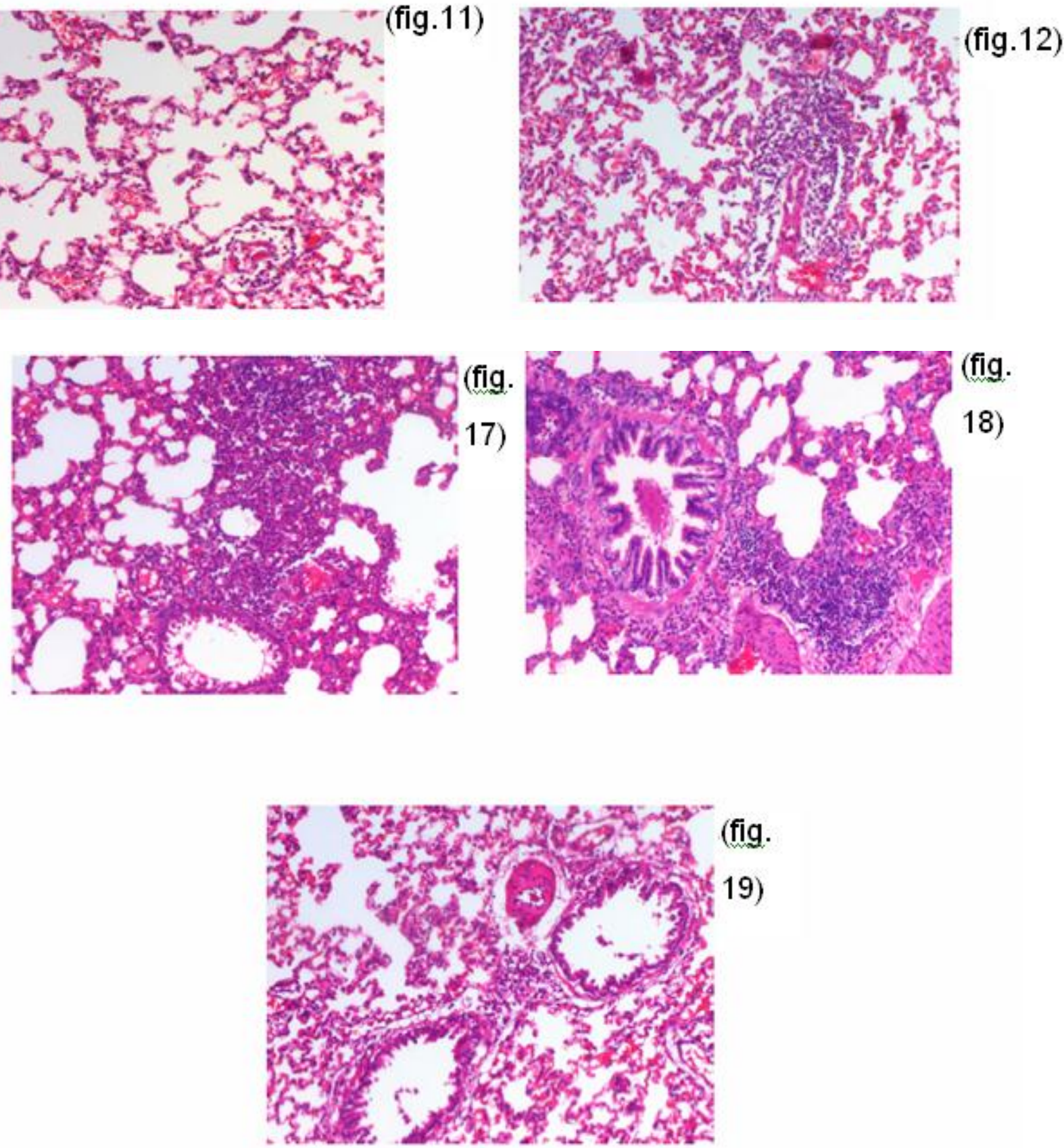

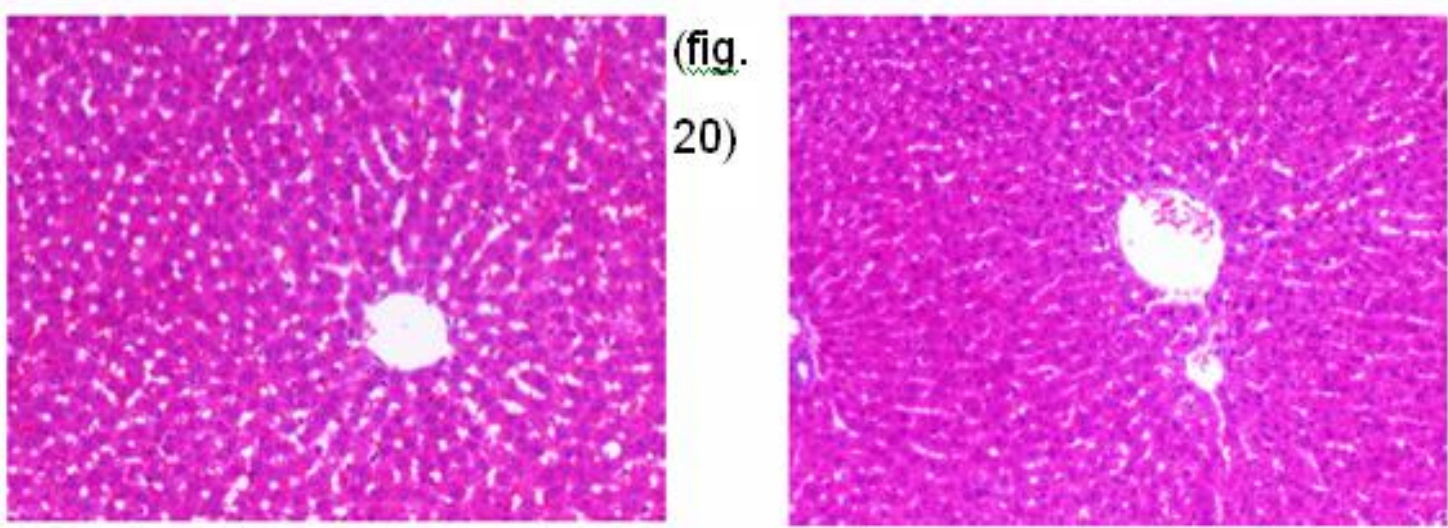

(fig.

21)
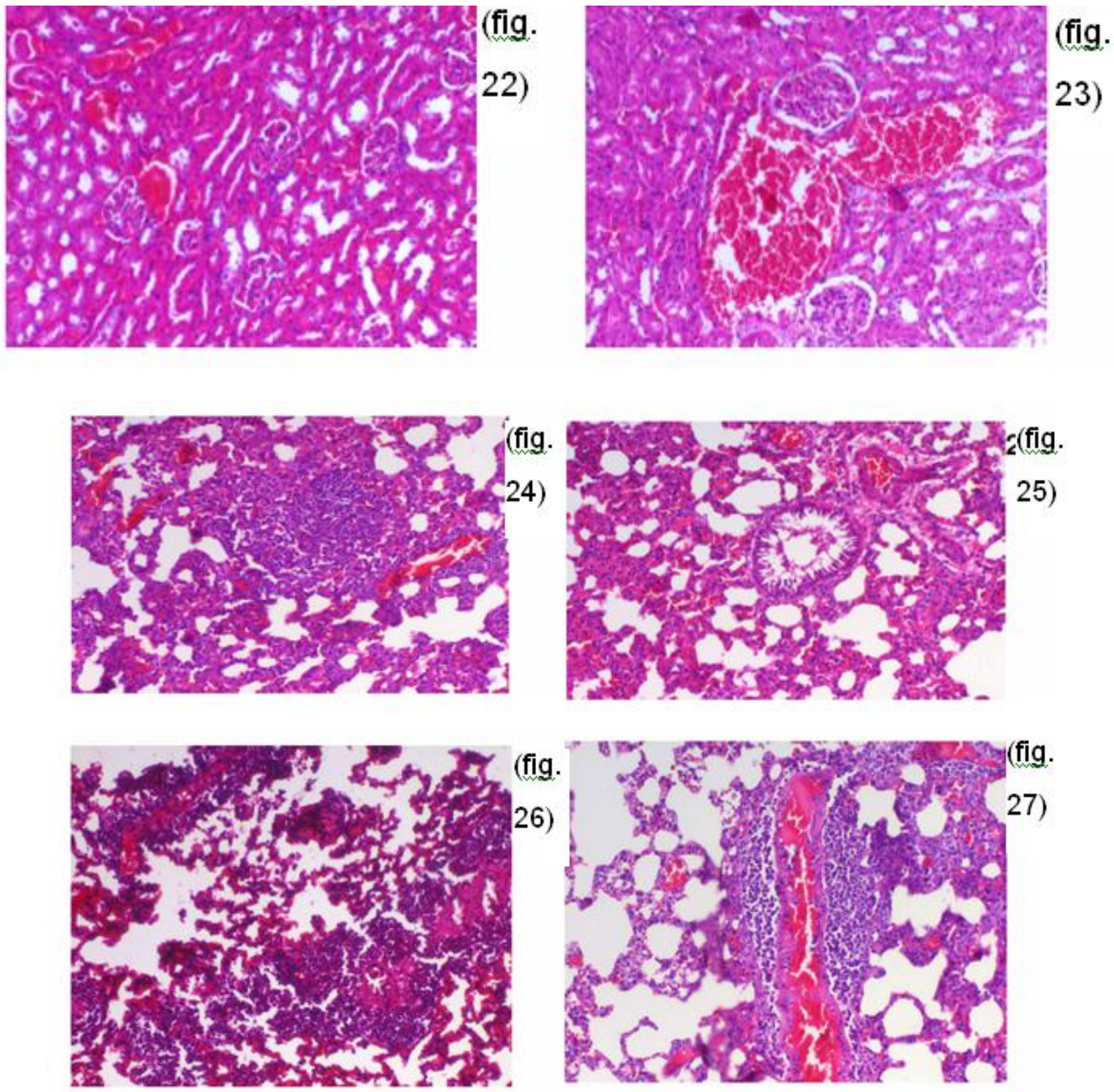

(fig

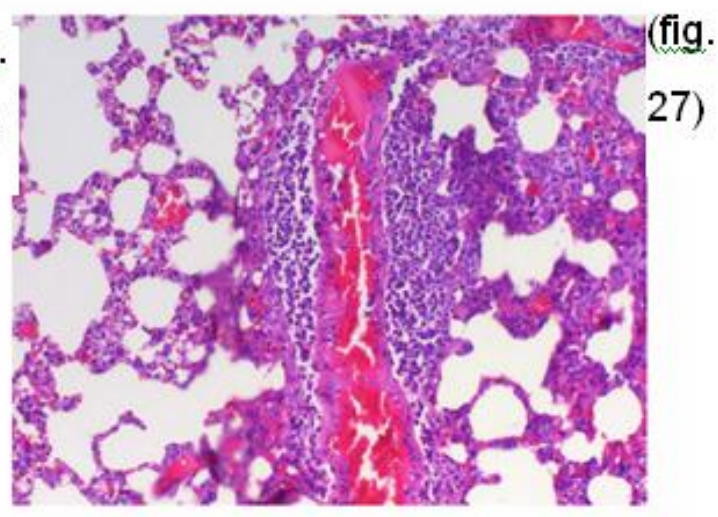



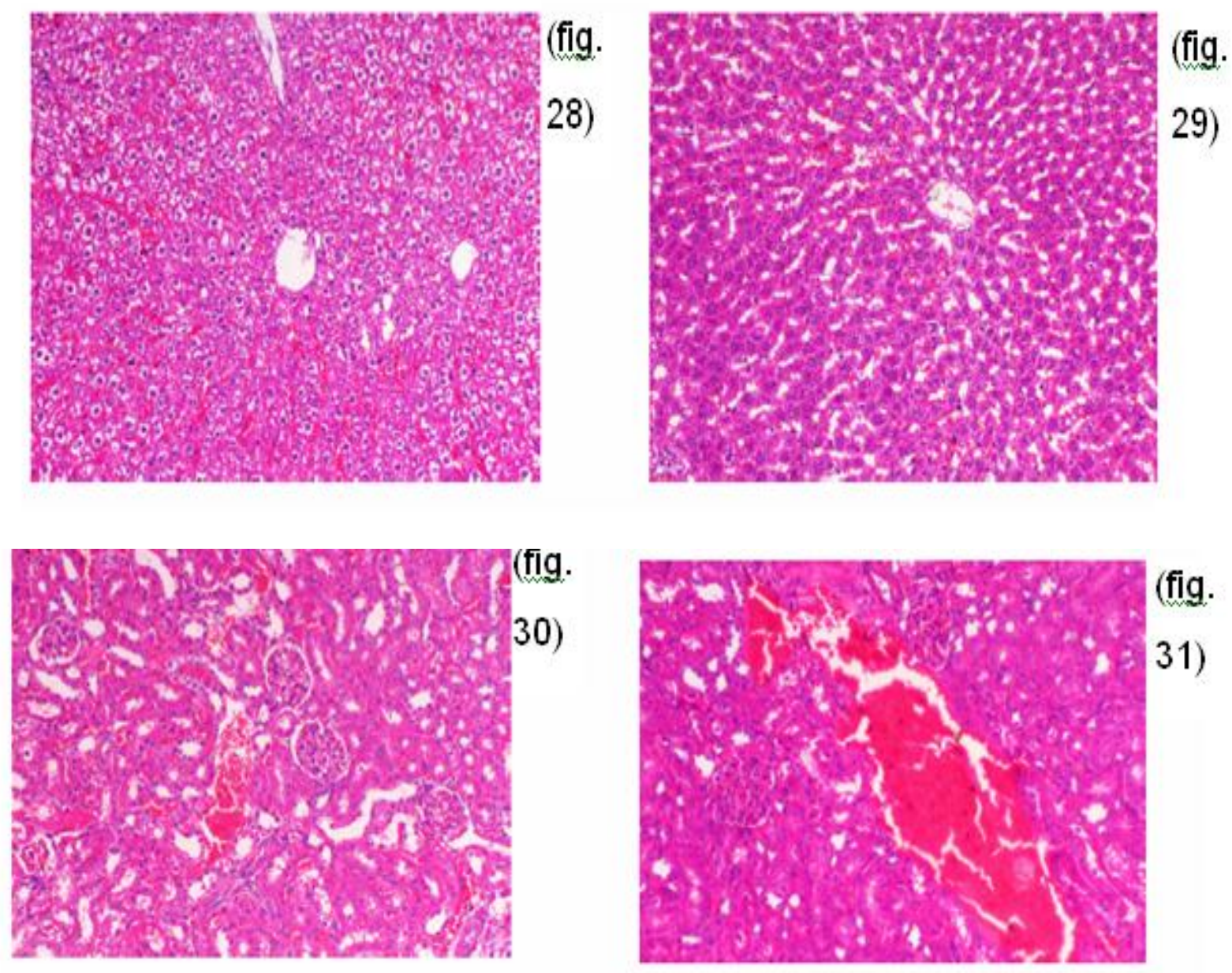


\section{Reference}

1. Anderson,(2013). Great Adventures in the Microbiology Laboratory (7th ed.). Pearson. pp. 175-176. ISBN 978-1-269-39068-2 (MacConkey)

2. Bancroft, J. D. \& Gamble, M. (2008). Theory and practice of histological techniques. 6th ed. Philadelphia, PA. Churchill Livingstone/Elsevier

3. Block S S. (1991)Historical review. In: Block S S, editor. Disinfection, sterilization, and preservation. 4th ed. Philadelphia, $\mathrm{Pa}$ : Lea \&Febiger; . pp. 3-17

4. Brumfitt, W.; Dixson, S.; Hamilton Miller, J.M.T.(1985) Resistance to antiseptics in methicillin and gentamicin resistant Staphylococcus aureus. Lancet i: 1442-1443,.

5. Denyer S P, Hugo W B,(1985) Harding V D. Synergy in preservative combinations. Int J Pharm.; 25:245-253.

6. Digison, MB, Retrieved 8 January,(2017)

" AReview of Antiseptic agent for pre operative skin preparation "plastic surgical nursing" official, Journal of the Amercan society of plastic and re Constructive surgical nurses 27 ( U) : 185-9

7. Gram H.(1884) uber dies isolertefarbung der schizomyceten in schnitt- und trockenpraparatens, fortschritte der medizin, 2: $185-189$

8. Hoppe J and schlagenhauf M.( 1989), comparison of three kinds of blood and two incubation atmospheres for cultivation of bordetalla pertussis on charcoal agar, J.clinMicrobiol 27: 2115-2117 (blood agar medium)

9. John Wiley \& sons, ( 2013) "encyclopedia of polymer science and technology

10. Kjellerup, Birthe (2015). "Elimination of Bloodstream Infections Associated with Candida albicans Biofilm in Intravascular

11. Klevens, R Moninaetal(2002) " Estimating Health care - ssociated infection and Death in u.s hospitals" public Health reports 122-2 (2007): 160-166

12. Lapages, Shelton J and Mitchell T.(1970) methods in microbiology, Norris $\mathbf{J}$ and ribbons d,eds,vol.3A, academic press, London (nutrient broth)

13. Larson E L(1996). Antiseptics. pp. 19-1. 19-7, G1-G17. In R. N. Olmstad (ed.), APIC infection control \& applied epidemiology: principles \& practices. Mosby-Year Book, Inc., St. Louis, Mo.

14. Leung M, Chan AH (March 2006). "Control and management of hospital indoor air quality"

15. Luis M. De LA Maza; Pezzlo, Marie T.; Janet T. Shigei; Peterson, Ellena $M$. (2004). Color Atlas of Medical Bacteriology. Washington, D.C: ASM Press. p. 103

16. MackConkey, 1905

17. McDonnell, G.; Russell (1999), D. Antiseptics and disinfectants: activity, 
action, and resistance. Clin. Microbiol. Rev.,12: 147-179, .

18. Pannutti, C.S.; Grinbaum, R.S. (1995) An Overview of nosocomial infection control in Brazil. Infect. Control Hosp. Epidemiol. 16: 170-174,

19. Persaud D, Perl TM, et al. (July 2005). "Nosocomial malaria and saline flush"

20. Reed land Muench H.(1938), Asimplemethodof estimating fifty percent end points, am .J.Hygience $27: 393-497$ (mouse lethality studies).

21. Russel AD (1999) - detergent resistance to Bacteria intensive care unit pathogens Plowman R, Graves N, Griffin M, Roberts JA, Swan AV, Cookson B, Taylor L. The socioeconomic burden of hospital acquired infection. London Public health laboratory service and the London school of hygiene and tropical Medicine.

22. Russel AD, chopra (1996) antiseptic resistance pattern of bacterial isolates in intersive care unit

23. Russell A D, Hugo W B, Ayliffe G A J, editors(1992). Principle and practices of disinfection, preservation and sterilization. 2nd ed. Oxford, England: Blackwell Scientific Publications Ltd.;

24. Russell A D, Hugo W B.(1987) Chemical disinfectants. In: Linton A H, Hugo W B, Russell A D, editors. Disinfection in veterinary and farm animal practice. Oxford,
England: Blackwell Scientific Publications; . pp. 12-42.

25. Russell A D, Russell N J.(1995) Biocides: activity, action and resistance. SympSoc Gen Microbiol.; 53:327-365.

26. Russell A D, Vernon G N.(1975) Inhibition by glutaraldehyde of lysostaphininducedlysis of Staphylococcus aureus. Microbios. ;13:147-149

27. Russell AD,fuee JR (1986) patterns of Antibiotic resistance, infect control HospEpidemiol

28. Russell, A. D.(1997) Plasmids and bacterial resistance to biocides: a review. J. App. Microbiol. 82:. 155-165, .

29. Salem M.(1997), increase of the bacteriostatic function macrophages against early infection with gram positive listeria mono ayto genes after treatment of mice with estradiol, J Egypt Gersoc zoo $133 i 347$ 378

30. SOKOL, W.N (2004) " Nine episodes of anaphylaxis following cystoscopy copy caused by cidexopA (ortho -, orthaladehyde) high- level disinfectant in 4 patients after cystoscopy "

31. Statewide,(2013) All-Payer Financial Incentives Significantly Reduce HospitalAcquired Conditions in Maryland Hospitals". Agency for Healthcare Research and Quality. 2013-07-03. Retrieved 201307-06. 
32. Wenzel RP(1995). The Lowbury Lecture. The economics of nosocomial infections. $J$ Hosp Infect.; 31:79-87. [PubMed]

33. Wenzel, R. P. and Edmond, M. B. (2001). The impact of hospital-acquired bloodstream infections. Emerging Infectious Diseases, $7(2), 174-177$.
34. Wilks, S.A., Michels, H., Keevil, C.W., (2005), The Survival of Escherichia Coli O157 on a Range of Metal Surfaces, International Journal of Food Microbiology, Vol. 105, pp. 445-454. and Michels, H.T. (2006), Anti-Microbial Characteristics of Copper, ASTM Standardization News, October, pp. 28-31-2007 cardodeniseetal 